\title{
The Increase of Power Efficiency of Underground Coal Mining by the Forecasting of Electric Power Consumption
}

\author{
Vladimir Efremenko ${ }^{1 *}$, Roman Belyaevsky ${ }^{1}$, and Evgeniya Skrebneva $^{1}$ \\ ${ }^{1}$ T.F. Gorbachev Kuzbass State Technical University, 650000, 28 Vesennyaya St., Kemerovo, Russia
}

\begin{abstract}
In article the analysis of electric power consumption and problems of power saving on coal mines are considered. Nowadays the share of conditionally constant costs of electric power for providing safe working conditions underground on coal mines is big. Therefore, the power efficiency of underground coal mining depends on electric power expense of the main technological processes and size of conditionally constant costs. The important direction of increase of power efficiency of coal mining is forecasting of a power consumption and monitoring of electric power expense. One of the main approaches to reducing of electric power costs is increase in accuracy of the enterprise demand in the wholesale electric power market. It is offered to use artificial neural networks to forecasting of day-ahead power consumption with hourly breakdown. At the same time use of neural and indistinct (hybrid) systems on the principles of fuzzy logic, neural networks and genetic algorithms is more preferable. This model allows to do exact short-term forecasts at a small array of input data. A set of the input parameters characterizing mining-and-geological and technological features of the enterprise is offered.
\end{abstract}

\section{Introduction}

The coal branch is one of the most power-intensive in economy of Kuzbass. The consumption of boiler-furnace fuel is more than $9 \%$, heat power is more than $19 \%$ and electric power is about $23 \%$ of all consumed energy resources by the region.

At coal enterprises in underground coal mining the share of the conditionally constant component of power consumption (ventilation, dewatering, lifting, compressor installations, etc.) is large [1]. In some mines, the share of these consumers accounts for more than $50 \%$ of all consumed electricity (Fig. 1).

"Corresponding author: brv.egpp@kuzstu.ru 


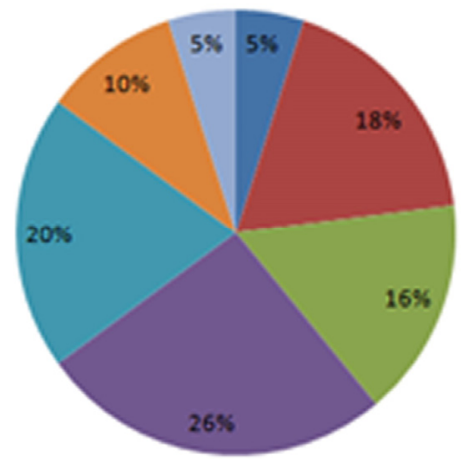

a Producing department

= Coal preparation plant

ar Drying

- Ventilation

a Coal mining

= Comeyance

ather

Fig. 1. The electric power consumption on technological processes of the coal mine.

Along with the increase in power consumption for the main technological processes, there is a constant increase in power consumption for drying and ventilation of mine workings (Fig. 2). This is due to the deterioration of mining and geological conditions of underground coal mining.

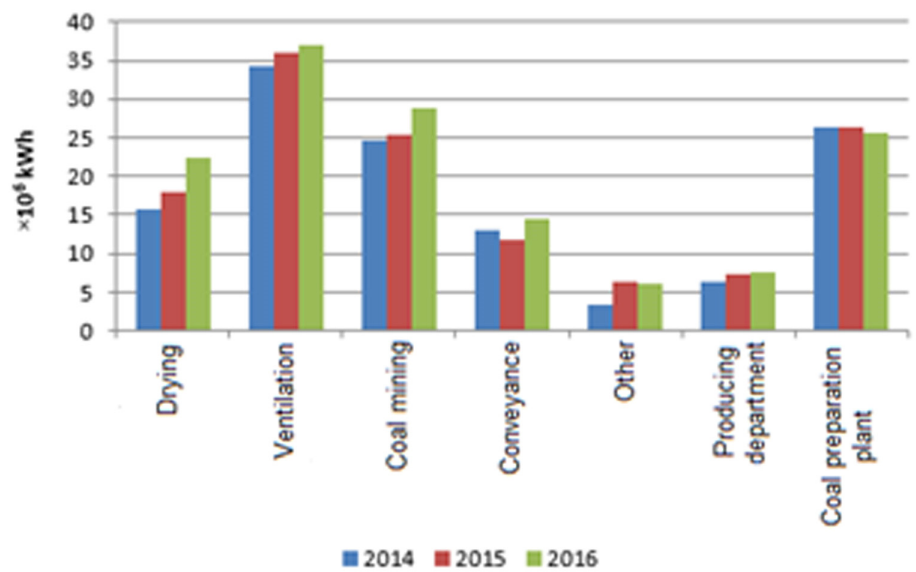

Fig. 2. The dynamics of power consumption in various parts of the coal mine.

The price and tariff policies that have changed in recent years in relation to energy resources and the increase in specific power consumption, have led to a significant increase in the energy component of the cost of production. For some mines, the energy component of the cost of production reaches $18-22 \%$. Analysis of the cost of coal mining shows that the energy component is uneven throughout the year, but has a pronounced seasonal character (Fig. 3). Maximum falls on the autumn and winter period. This is due to increased fuel consumption in own boiler houses and increased power consumption during this period (boiler equipment, heaters, lighting, etc.). 


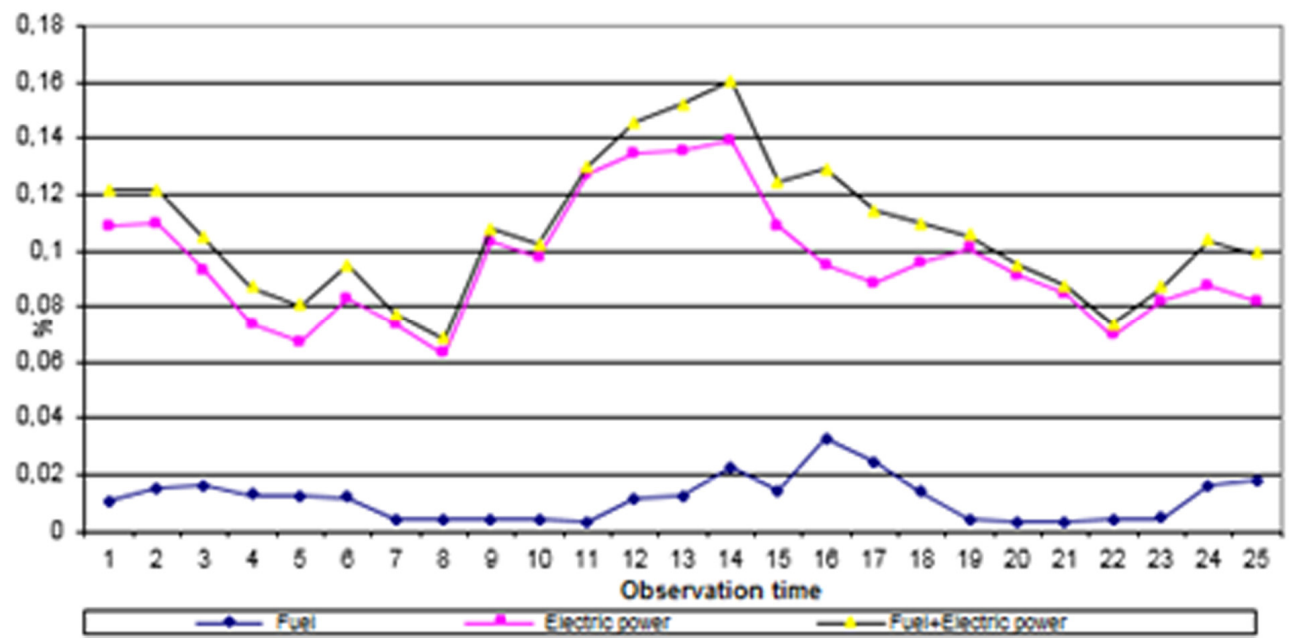

Fig. 3. The change of the energy component of coal production costs.

The long-term program of development of the coal industry of Russia until 2030, along with other purposes, provides for ensuring of competitiveness in the markets, primarily by reducing the cost of coal mining and processing. Experience shows that with the energy component in the production cost of more than $10 \%$, energy-saving measures are required. However, at present power saving in the coal industry is not going to be intensive enough. Nevertheless, the power saving potential is high and amounts to $15-30 \%$ of annual consumption in the complex solution of power saving problems $[2,3]$. It means that saving fuel fuel and energy resources in coal mines requires serious attention.

\section{Materials and Methods}

When considering the problems of energy resources saving in coal mines, the following main areas should be singled out:

- boiler-furnace fuel saving;

- thermal power saving;

- electric power saving;

- other measures that increase the power efficiency.

In this article, measures aimed at boiler-furnace fuel saving and thermal power saving, as well as other measures related to the change in the technology of coal mining and processing, are not considered.

Let us dwell on the main directions of electric power saving. In electric grids of coal mines, consisting of branched transmission lines, transformers, electric machines and apparatus, up to $20 \%$ of the consumed electric power is lost. This is due to many reasons, including the irrational construction and operation of networks in suboptimal mode. It is caused by the deviation of the actual state of production from the design state. This is expressed in the deviation of the centers of electrical loads from the places of installation of transformers, the overloading of some lines and the underload of others, the lack of optimal reactive power compensation, and the reduction of electric power quality. As a result, in the networks of coal mines there are significant power losses. Experience has shown, only the elimination of the above shortcomings through the holding of different technical measures will reduce the power losses by half.

Another important direction in reducing of electric power costs is the forecasting and monitoring of electric power consumption. 
Enterprises through their energy sales organizations participate in power trading on the day-ahead market and the balancing market [4]. Day-ahead market assumes that the price for electric power is determined by the consumer demand and the proposal of suppliers during the auction. The balancing market plays the role of a mechanism that ensures a balance between supply and demand with possible deviations in the production and consumption of electric power from the forecasted parameters the next day. In the event of a deviation of the actual electric power consumption from the application, the electric sales organizations either sell surpluses or purchase the missing electric power in the balancing market. This is unprofitable for enterprises, as the prices of the balancing market take into account the need to cover the costs associated with the redistribution of electric power.

As the installed power of the electric receivers is much higher than $670 \mathrm{~kW}$, for the mines there is a choice from the third to the sixth price category. This requires the provision of an hourly demand for electric power consumption for the next day.

Analysis of costs associated with the acquisition of electric power, shows that the enterprise can actually reduce the cost of electric power by changing the planned electric power consumption and reducing the deviation of actual consumption from the declared. In other words, this is achieved through a more accurate prediction of electric power consumption for the day ahead.

Elimination of power losses in case of deviation of actual consumption from planned consumption is possible due to strict limitation. In this case, the power consumption is limited when approaching the planned value. Also, the elimination of power losses is possible due to the use of forecasting methods based on analysis and consideration of all factors affecting on electric power consumption. The first method in conditions of coal mines is practically difficult to implement, because there are electric receivers providing safe conditions under the ground. Restriction of other energy-intensive consumers can lead to long-term destruction of technological processes. In this case, economic damage can significantly exceed the possible additional costs to acquiring of electric power in a balancing market.

At present, the demand for the electric power consumption is formed empirically. It is based on previous experience, including the experience of the person responsible for this direction. Adoption of optimal solutions in a complex rapidly changing environment requires a high qualification of the person making the decision and the use of modern decision-making methods. It should be noted that the specialists for predicting of electric power consumption do not always have the necessary competences for optimal power management. At the same time, many foreign companies have special power management services. In some countries, such as the USA, Japan, etc., this is determined by law [5].

In general, the problem of optimal control of electric power consumption when working in the day-ahead market is to provide an application for electric power under the influence of various factors. As a criterion for optimization, the minimum of deviations of the actual and declared power consumption (the minimum of the error of the application) is taken.

The forecast system should be a real-time system. It means that electric power consumption has to be formed under the influence of various internal and external factors that change in real time. The high dynamism and uncertainty of the impact make it necessary to quickly solve problems, and sometimes even ahead of schedule. At the same time, the "control clock", that is, the time interval for forecasting is set by the requirements of the wholesale market based on the hourly forecast for the next day.

Factors affecting power consumption can be divided into external and internal. External factors affect electric power consumption, but these factors can not be influenced by the entity (enterprise), for example, gas and water profuseness, depth and thickness of coal seams. Internal factors arise from the activities of the enterprise. These factors change in order to optimize electric power consumption (production volume, structural and technological factors, social and economic factors, etc.). 
To solve the problem of forecasting electric power consumption, traditional statistical methods based on specific norms for electric power consumption and models based on expert systems and artificial neural networks can be used [6-9].

Traditional statistical methods have the following disadvantages:

- direct participation of analysts at their application;

- complexity of calculations;

- inadequate forecast accuracy;

- the ability to apply only to a certain type of forecast;

- sensitivity to input parameters $[10,11]$.

Artificial neural networks are more preferable. In this case, there is no need to build a consumer model and the operability is not lost with incomplete input data. Besides, artificial neural networks have high speed and stability. It is preferable to use the configuration of artificial neural networks of direct propagation (perceptrons) with learning by the back propagation error method, even in spite of the slow convergence. Sometimes training of perceptrons takes a several days. It is important to consider the number of hidden layers and neurons in these layers. Low number of neurons provides poor training and malfunction. A large number of neurons gives a long learning process. Then the network can not be suitable for solving this problem at all. As a rule, the number of neurons in a hidden layer is determined experimentally. For this, it is necessary to put several experiments with different network configurations by the number of neurons in the hidden layer and compare the results of training [11-13].

\section{Results and Discussions}

The forecasting system based on an artificial neural network allows us to analyze groups of electric power consumers taking into account poorly formalized and nondeterministic factors. It allows to increase the accuracy of the forecast for electric power consumption.

The change in the level of electric power consumption is a nonlinear function and its prediction needs to be made in real time. For these purposes, it is preferable to use neuronfuzzy systems, which belong to the class of hybrid systems. The fuzzy logic, neural networks and genetic algorithms are the cornerstone of these systems. This model allows you to make accurate short-term forecasts with a small amount of input data.

To increase the level of forecasting, it is necessary to divide all electric power receivers into homogeneous classes in terms of technological parameters and power efficiency. In this case, the architecture and factors of the artificial neural network (neural-fuzzy system) are selected separately for each class.

It is necessary to solve two main tasks:

1. To carry out the analysis of structure of electric power consumption of the research object.

2. To construct a predictive model of electric power consumption based on the data of the analysis [15].

With a known coal production plan for the next period and factors characterizing the mining, geological, and technological conditions of coal mining, a multifactor model based on an artificial neural network (neural-fuzzy system) is adequate and acceptable for planning of electric power consumption for a next day or other period.

To increase the level of forecasting of electric power consumption it is necessary to use individual models characterizing the individual features of each enterprise. It is also possible to carry out preliminary classification of mines by cluster analysis methods taking into account mining, geological, and technological parameters that affect the level of electric power consumption. However, the number of factors should not be large, since this will lead to more complicated analysis and practical use of the results. 
For the selection of factors, the Delphi method was used. This method made it possible to select five factors, which in aggregate fully characterize the size of enterprises, their technological, mining and geological features. In addition, the selected factors are easily determined both during the operation of the mine and at the stage of its design:

$W$ - this parameter determines electric power consumption for mining, transport, lifting and processing of coal at existing surface complexes, as well as the required power of the electric drive of mining vehicles and machinery, $\mathrm{t} / \mathrm{h}$;

$m$ - average dynamic thickness of the seams determines the choice of equipment for the integrated mechanization and automation of coal mining, $\mathrm{m}$;

$Q$ - water profuseness determines the number of pumping installations of the main dewatering system and the power of electric motors, $\mathrm{m}^{3} / \mathrm{h}$;

$V$ - gas content of layers determines the ventilation system, the number of fan units and the power of their electric motors, $\mathrm{m}^{3} / \mathrm{h}$;

$H$ - depth of the mine determines the power and operation modes of the lifting installations, $\mathrm{m}$.

\section{Conclusions}

Thus, the important direction of increase of power efficiency of coal mining is forecasting of a power consumption and monitoring of electric power expense. One of the main approaches to reducing of electric power costs is increase in accuracy of the enterprise demand in the wholesale electric power market. To forecasting the day-ahead electric power consumption, it is necessary to use artificial neural networks. When using artificial neural networks (neuralfuzzy systems), along with informational and computational tasks (choice of neural network structure, learning strategies, application of fuzzy inference strategy, etc.), it is necessary to define a set of input parameters that determine the electric power consumption in the mine. These factors should be presented and fully characterize the variety of conditions for underground coal mining.

The order of construction of the economic-mathematical model is the following:

1. To identify a research object (the mine as a whole or a separate technological site).

2. To formulate the purpose of researches as minimizing deviations of actual and planned values of electric power consumption.

3. Within the framework of the research object, to identify the structural and functional elements that most significantly affect the achievement of the stated purpose.

4. To construct a mathematical model of electric power consumption in a coal mine.

5. To carry out calculations for the model and analyze the results. If the results are unsatisfactory, the process of electric power consumption should be analyzed in more detail, taking into account a wider set of factors.

\section{References}

1. V. Efremenko, R. Belyaevsky, MINING 2014: Taishan Academic Forum - Project on Mine Disaster Prevention and Control, 190 (2014)

2. J.W. Taylor, R. Buizza, Intern. J. Forecasting, 19, 57 (2003)

3. T. Mount Decision Support Syst., 30, 311 (2001)

4. K. Metaxiotis, A. Kagiannas, D. Askounis, J. Psarras, Energy Conversion and Management, 44, 1525 (2003)

5. F.B. Verona, M. Ceraolo, Neurocomputing, 23, 135 (1998)

6. A.K. Topalli, I. Erkmen, Neurocomputing, 51, 495 (2003) 
7. S. J. Yao, Y. H. Song, L. Z. Zhang, X. Y. Cheng, Energy Conversion and Management, 41, 1975 (2000)

8. B. Kermanshahi, H. Iwaminya, Electrical Power and Energy Syst., 24, 789 (2002)

9. V. Kodogiannis, E. Anagnostakis, Fuzzy Sets and Systems, 128, 413 (2002)

10. M. Hudson Beale, M. Hagan, H. Demuth, Natick: MathWorks, 22, 255-271 (2014)

11. J. Nowicka-Zagrajek, R. Weron, Signal Processing, 82, 1903 (2002)

12. H.C. Huang, R.C. Hwang, J.G. Hsieh, Electrical Power and Energy Syst., 24, 245 (2002)

13. D. Srinivasan, S.S. Tan, C.S. Chang, E.K. Chan, IEE Proc. Gener. Transm. Distrib, 145:6, 409 (1998) 
